\title{
One-splint versus two-splint technique in orthognathic surgery for class III asymmetry: comparison of patient-centred outcomes
}

\author{
Jing Hao $\mathrm{Ng}^{1}$ (1) $\cdot$ Ying-An Chen ${ }^{2,3,4} \cdot$ Yuh-Jia Hsieh ${ }^{2,3,5} \cdot$ Chuan-Fong Yao ${ }^{2,3,4} \cdot$ Yu-Fang Liao ${ }^{2,3,5,6} \cdot$ Yu-Ray Chen ${ }^{2,3,4,6}$
}

Received: 1 September 2020 / Accepted: 22 April 2021 / Published online: 5 May 2021

(C) The Author(s) 2021

\begin{abstract}
Objectives Two-jaw orthognathic surgery (OGS) is done using either the one-splint technique with free-hand positioning of the maxillomandibular complex or the two-splint technique with intermediate splints to position the maxilla. It is uncertain which technique achieves better outcomes. This study compares frontal soft tissue symmetry and subjective patient QoL between onesplint and two-splint techniques in skeletal Class III asymmetry patients undergoing OGS with three-dimensional surgical planning. Materials and methods This retrospective case-control study comprised 34 one-splint and 46 two-splint OGS patients. Frontal photographs and Orthognathic Quality of Life Questionnaire (OQLQ) were done pre- and post-treatment. Frontal soft tissue symmetry was analysed with the anthropometric Facial Symmetry Index. Measurements were compared with $t$-tests and chisquared tests with $p$-value set at 0.05 .

Results The groups differed in pre-treatment ANB and OQLQ scores. The two-splint group showed significant improvement in all symmetry measures. The one-splint group showed significant improvement in all symmetry measures except midface deviation, upper contour deviation and the Facial Contour Symmetry Index. Both groups showed significant improvement in OQLQ scores. There were no significant differences in post-treatment symmetry measurements and OQLQ scores between groups.

Conclusions Although two-splint technique may better improve contour symmetry, there were no significant differences in frontal soft tissue symmetry and QoL after OGS in skeletal Class III asymmetry with either one-splint or two-splint technique, with both techniques resulting in significant improvement.

Clinical relevance One-splint and two-splint surgical techniques produce similar patient-centred outcomes in Class III asymmetry patients.
\end{abstract}

Keywords Quality of life · Clinical outcomes · Comparative effectiveness research (CER) $\cdot$ Facial symmetry $\cdot$ Orthognathic surgery $\cdot$ One-splint

Yu-Fang Liao

yufang@cgmh.org.tw

1 Department of Orthodontics, National Dental Centre Singapore, Singapore, Singapore

2 Craniofacial Center, Chang Gung Memorial Hospital, Taoyuan, Taiwan

3 Craniofacial Research Center, Chang Gung Memorial Hospital, Linkou, Taiwan

4 Department of Plastic and Reconstructive Surgery, Chang Gung Memorial Hospital, Linkou, Taiwan

5 Department of Craniofacial Orthodontics, Chang Gung Memorial Hospital, Taoyuan, Taiwan

6 College of Medicine, Chang Gung University, Taoyuan, Taiwan

\section{Introduction}

Patients with facial asymmetry frequently undergo bimaxillary orthognathic surgery (OGS) for improvement of dentofacial symmetry and aesthetics [1-4]. Two-jaw OGS can be carried out either using the one-splint technique with freehand positioning of the maxillomandibular complex (MMC) [5-7] or the two-splint technique with intermediate splints to position the maxilla [8].

Prior to 2003, the authors' Craniofacial Center used the classic two-splint OGS technique with two-dimensional (2D) surgical planning with mounted plaster models and lateral and postero-anterior cephalograms. After 2003, due to less than ideal results with the two-splint technique, a onesplint technique using only the final occlusal splint with free-hand positioning of the MMC was developed [6, 7]. 
Mild under- or over-correction of hard tissue asymmetry was used to achieve soft tissue symmetry, with intra-operative assessment needed due to patient variability in soft tissue response $[6,7,9]$. This was validated by Kim et al. [10], who found that the average amount of lip cant correction was approximately $50 \%$ of the maxillary occlusal cant correction. With 2D planning, the one-splint technique produces good results in asymmetry patients $[6,11]$. It also reduces technical effort because only one splint is fabricated. However, whilst diagnosis, surgical planning and treatment outcomes are assessed with the patient upright and with relaxed soft tissues, the one-splint technique relies on supine intra-operative assessment of the patient with soft tissues that are invariably distorted by airway intubation. This introduces added complexity to the one-splint technique. The technique is hence surgically demanding, has a steep learning curve and depends heavily on surgeon experience $[7,12,13]$.

In 2015, the Center started virtual orthognathic planning using three-dimensional (3D) software, cone beam computed tomography $(\mathrm{CBCT})$, photographs and digital dental casts. Using 3D planning with one-splint technique achieves good hard and soft tissue results in asymmetry patients [13-16] and seems to outperform 2D surgical planning with one-splint technique in terms of hard tissue gonial symmetry and yaw symmetry achieved [14] as well as improvement in soft tissue facial midline asymmetry [16].

However, even when the 3D simulation and a detailed 3D surgical plan are provided, the MMC movement is greatly dependent on the surgeon's intra-operative assessment of the checkpoints when using the one-splint technique $[13,14]$. The onesplint technique produces significant deviation from the 3D surgical plan, with a relatively poor landmark accuracy of $1.5 \mathrm{~mm}$ at the maxilla and $2 \mathrm{~mm}$ at the mandible, with MMC pitch showing the greatest error [13]. From 2015, due to the desire to translate the precise 3D-planned skeletal movements to the surgery, the surgical team shifted from one-splint to two-splint technique with a 3D printed intermediate splint. This required greater technical effort to produce two surgical splints, as well as reduced intra-operative flexibility in changing the surgical planning. The benefit of the two-splint technique is having surgical planning done in the upright patient being congruently translated into the intra-operative and post-operative condition, rather than depending on a supine intra-operative condition to decide the MMC position as in the one-splint technique [13, 14, 17, 18].

From 2015 to 2016, the Center principally used the onesplint technique with 3D planning and, from 2017 onwards, predominantly used the two-splint technique with $3 \mathrm{D}$ planning. It is uncertain which technique achieves better outcomes. This study aims to compare frontal soft tissue symmetry and subjective patient-reported health-related quality of life $(\mathrm{QoL})$ between one-splint and two-splint techniques in skeletal Class III asymmetry patients undergoing OGS with 3D surgical planning.

\section{Methods}

\section{Subjects}

This retrospective case-control study comprised patients identified from the Center's database. All patients meeting the following selection criteria were included in the study: at least 18 years of age with stable body height, skeletal Class III with ANB angle $\leq 0$ degree, facial asymmetry with significant menton deviation $\geq 4 \mathrm{~mm}$ as assessed on a frontal cephalogram [19-21] or significant contour asymmetry assessed by an orthodontist (L.Y-F) on frontal photos, had bimaxillary OGS from year 2015 to 2019 with LeFort I and bilateral sagittal split osteotomy (BSSO) using a surgery-first approach by a single team of surgeons using either the onesplint or two-splint technique with 3D surgical planning, surgical planning and post-surgical orthodontic treatment performed by a single orthodontist (L.Y-F), availability of patient-reported questionnaires completed before surgery (pre-treatment) and after orthodontic debonding (post-treatment), availability of digital photographs taken before orthodontic and OGS treatment (pre-treatment) and after orthodontic debonding (post-treatment) and the absence of congenital craniofacial anomalies. The study was conducted in accordance with the Helsinki Declaration [22] and reported according to the Strengthening the Reporting of Observational Studies in Epidemiology (STROBE) guidelines [23].

\section{Surgical planning}

3D virtual orthognathic planning was done using Dolphin Imaging (Patterson Dental Supply, Winsconsin, USA) by the treating orthodontist based on CBCT, photographs and dental casts taken 1 month before OGS. The laboratory procedures were described in Liao et al. [16] and planning principles detailed in Liao et al. [24]. Surgical movements were planned to achieve hard and soft tissue symmetry based on individual diagnosis and clinical examination. The surgical splints were virtually designed and printed with 3D rapid prototyping using Objet30 OrthoDesk (Stratasys Ltd. Minnesota, USA).

\section{One-splint surgical technique}

The MMC was completely mobilised with a LeFort I osteotomy and a BSSO, with or without segmental osteotomies. It was then put into intermaxillary fixation with the final occlusal splint. The MMC was repositioned based on the 3D plan, and metal wires on the best bone contact sites of the right and left maxilla were used to temporarily fix the MMC to the stable upper maxillary base (Fig. 1), with the metal wire suspension accommodating small adjustments of the maxillomandibular complex position based on the 


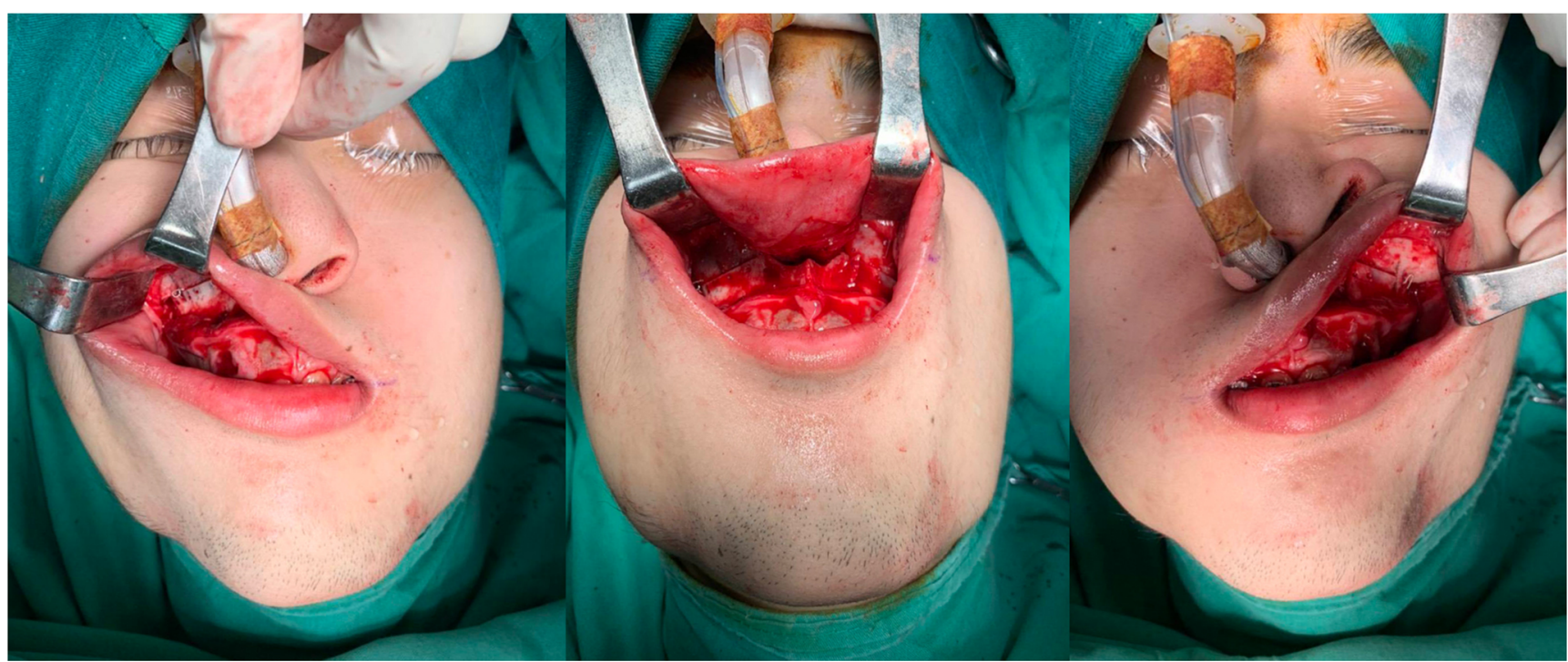

Fig. 1 One-splint technique — wire fixation used to suspend the MMC whilst making intra-operative measurements

following intra-operative checkpoints: (1) midline coordination, (2) upper incisor show, (3) intercommissural line, (4) frontal contour symmetry, (5) frontal cheek symmetry, (6) paranasal fullness, (7) Ricketts E-line and (8) lower face proportions (Fig. 2).

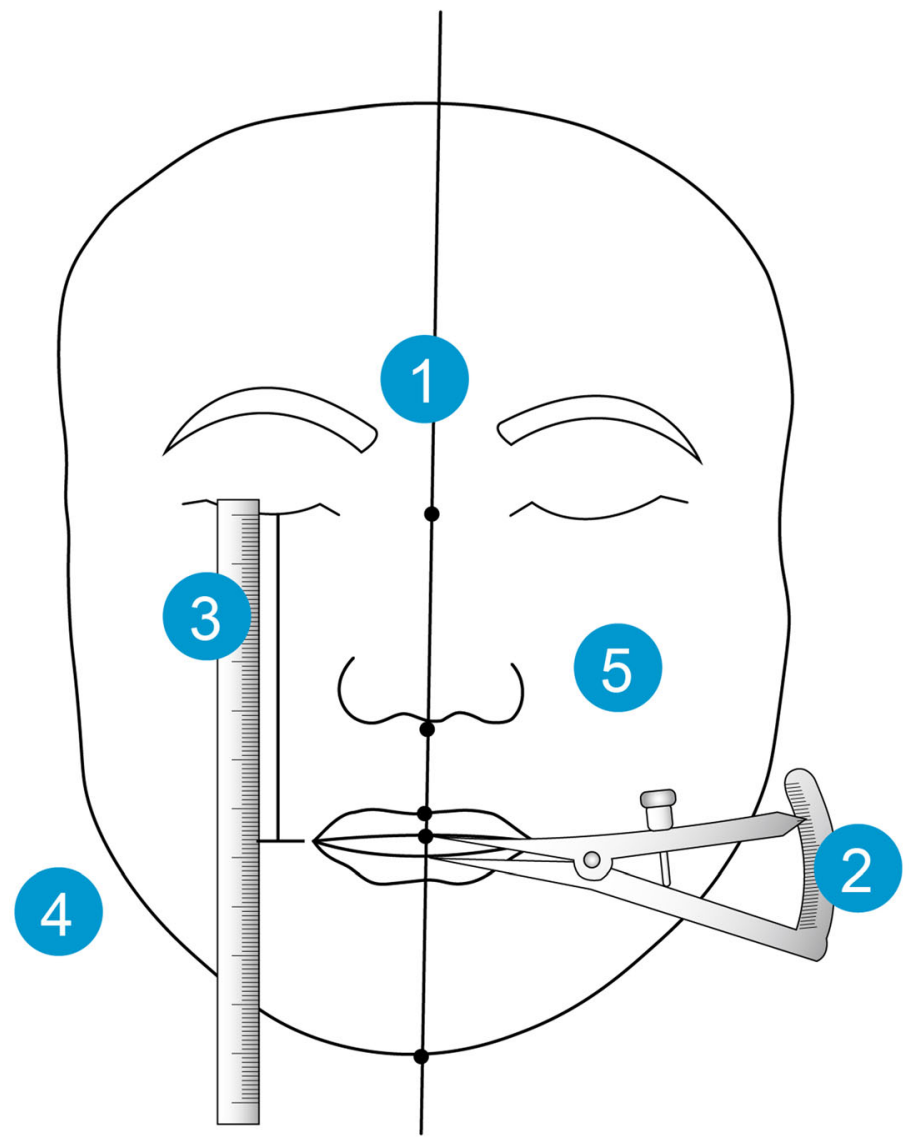

(1) Midline coordination was done from a true anteroposterior view. The soft tissue glabella, subnasale, midline of Cupid's bow and chin point were marked with ink and aligned, together with the maxillary inter-incisive line, onto the facial midline decided by

Fig. 2 One-splint technique - schematic of intra-operative checkpoints: (1) midline coordination, (2) upper incisor show, (3) intercommissural line, (4) frontal contour symmetry, (5) frontal cheek symmetry, (6) paranasal fullness, (7) Ricketts E-line, and (8) lower face proportions 
$3 \mathrm{D}$ virtual plan. When all the above landmarks could not be aligned perfectly, the alignment of the maxillary inter-incisive line with the midline of Cupid's bow was prioritised. The remaining landmarks were lined up as best as possible by altering the MMC position. The lateral displacement of the nose due to nasal intubation was taken into account when performing midline coordination. The need for chin point correction with genioplasty was also assessed.

(2) The upper incisor show was measured and adjusted to between 2 and $3 \mathrm{~mm}$. Incisive show was modified by changing the amount of maxillary anterior impaction or extrusion and the amount of maxillary setback or advancement. Care was taken on this step as the nose is often displaced superiorly due to nasal intubation and maxillary exposure.

(3) The distances from the left and right lip commissure to the corresponding lower eyelid were measured to be consistent with $3 \mathrm{D}$ virtual plan. In the absence of an eye cant, the distances should be similar on both sides. Altering the MMC roll by burring or grafting the zygomaticomaxillary buttress was done to change the position of the corresponding commissure and obtain better symmetry.

(4) Frontal facial contours were visually assessed from a true antero-posterior view and were altered by modifying the MMC yaw, with the axis of rotation being the anterior maxillary midline. Need for genioplasty or mandibular contouring to improve contour symmetry was assessed at this time.
(5) Frontal cheek fullness should be symmetrical and was altered by modifying the MMC yaw.

(6) Laterally, paranasal fullness or depression was assessed and adjusted by modifying the antero-posterior position and pitch of the MMC.

(7) Laterally, the need for advancement or setback genioplasty was confirmed by verifying the Ricketts E line with a ruler.

(8) The classic lower face proportions (subnasale to intercommissural plane, one-third; intercommissural plane to chin point, two-thirds) were checked to assess the need for chin elongation or shortening with genioplasty.

After the MMC position was confirmed, titanium bone plates and screws were used for rigid fixation and placed at the maxilla first, followed by the mandible. Genioplasty or mandibular contouring was performed as needed based on the above intra-operative assessments, and all checkpoints were re-verified (Fig. 3).

\section{Two-splint surgical technique}

All patients in the two-splint technique group underwent a maxilla-first sequence. Pre-surgically, an additional bite registration with $3-8 \mathrm{~mm}$ bite opening was taken in supine position to obtain an open-mouth maxillomandibular registration and used to reduce inaccuracies in mandibular autorotation and eliminate interferences in the intermediate surgical splint. LeFort I osteotomy with or without segmental osteotomy was

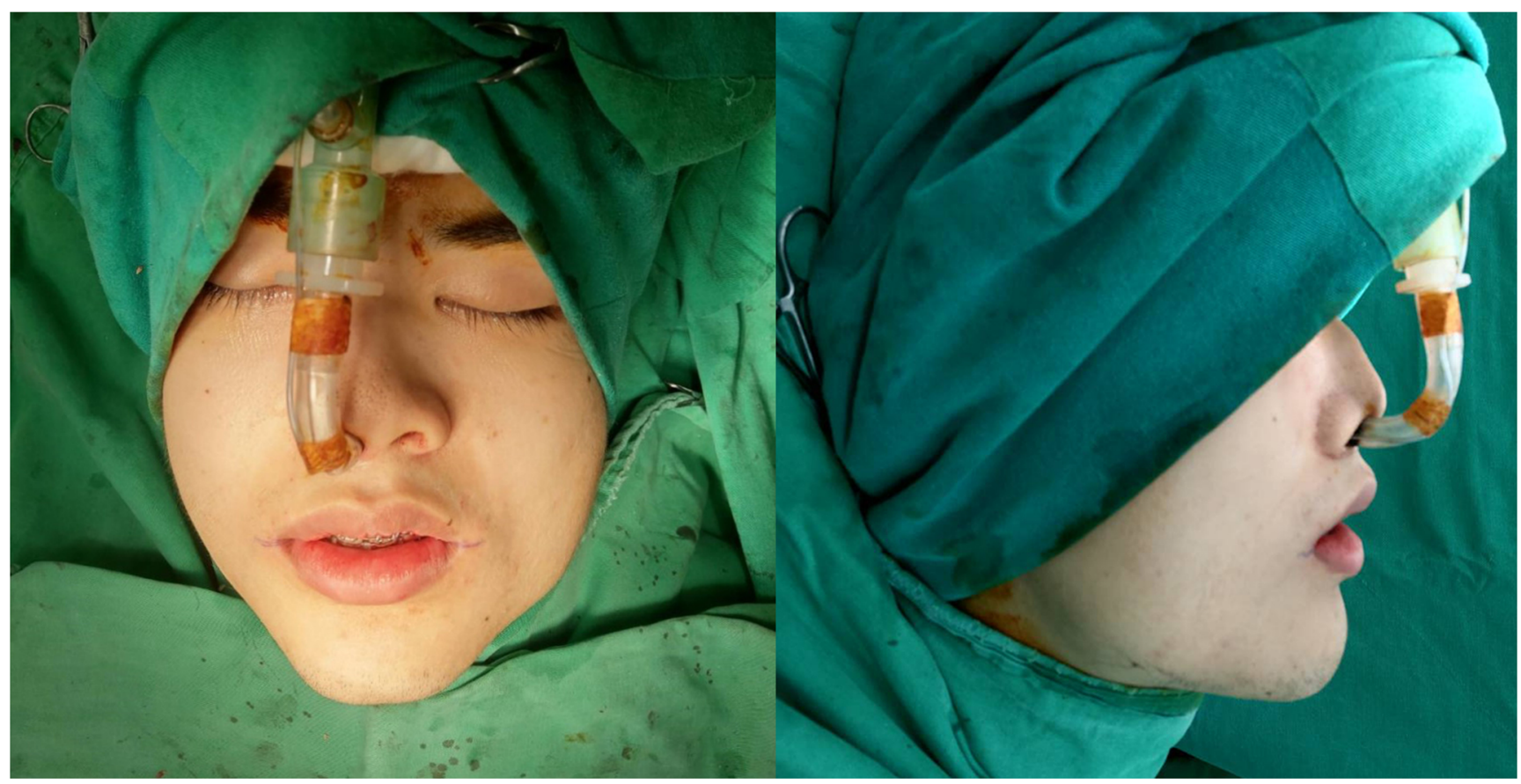

Fig. 3 One-splint technique — intra-operative view for making measurements and verifying checkpoints 
used to mobilise the maxilla. Intermediate splint was used with intermaxillary wiring to form the intermediate MMC (Fig. 4), which moves according to bilateral temporomandibular joints and guides the position of maxilla. The vertical position of maxilla was adjusted according to the planned movements, after which titanium bone plates and screws were used for rigid fixation of the intermediate MMC. Intermaxillary wiring was released, and BSSO was done on the mandible and positioned using the final splint (Fig. 5) before the final mandible position was confirmed. Titanium bone plates and screws were used for rigid fixation of the mandible. Genioplasty or mandibular contouring was performed as needed based on intra-operative assessment of soft-tissue profile, proportion and symmetry.

\section{Soft tissue analysis}

Frontal photographs were taken pre-treatment and post-treatment. A professional photographer used a Canon EOS 350D digital camera (Canon, Inc., Tokyo, Japan), with the resolution set at $2496 \times 1664$ pixels to photograph patients according to the photographic standards of the European Association for Cranio-Maxillo-Facial Surgery [25, 26].

Seven angular anthropometric measurements were made on the digital photographs (Figs. 6, 7 and 8). These were performed with Photoshop 9.0 (Adobe Systems, Inc., San
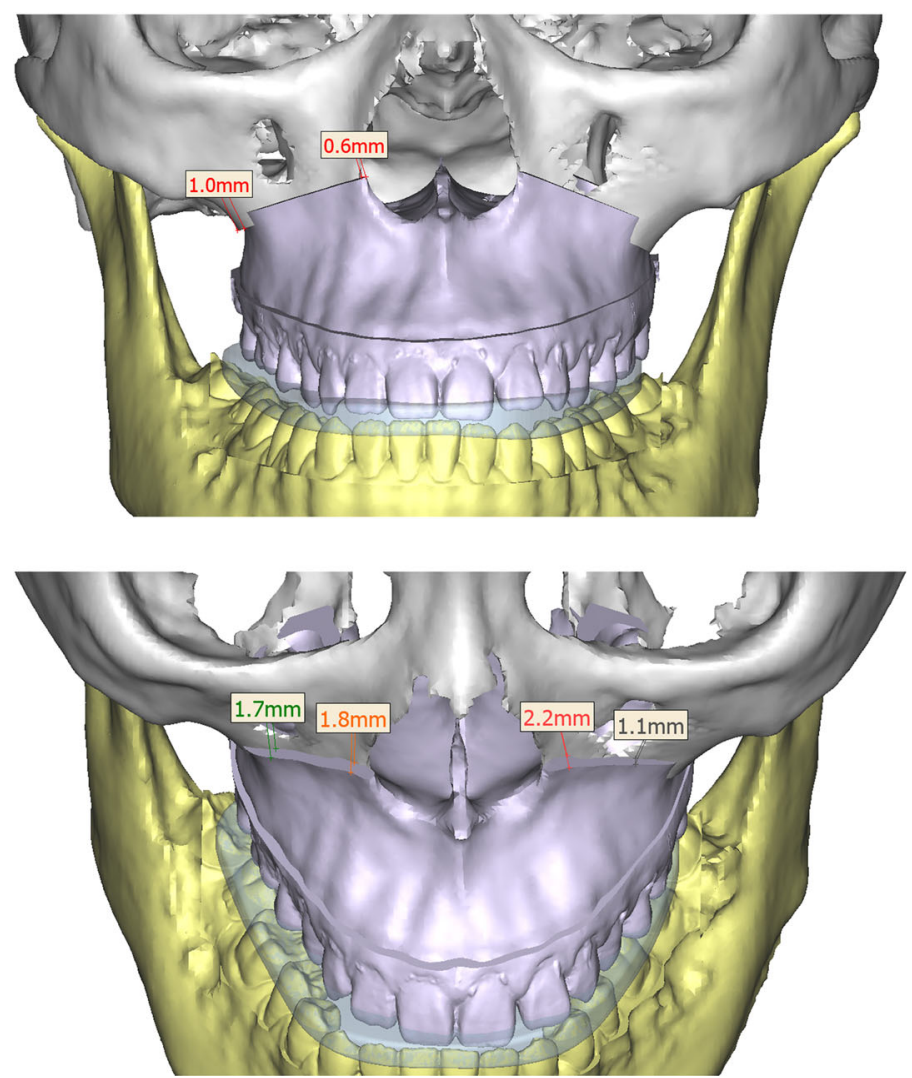

Jose, CA, USA) by an experienced researcher. The seven measurements constituted the Facial Symmetry Index, which is adapted from the Facial Midline Symmetry Index [7] and has been validated in previous studies $[15,16]$. The index comprises one lip cant measurement (Fig. 6), three midline facial measurements (Fig. 7) and three facial contour measurements (Fig. 8). The three midline measurements are combined into a Facial Midline Symmetry Index, whilst the three contour measurements are combined into a Facial Contour Symmetry Index. All seven measurements are combined to calculate an Overall Facial Symmetry Index. The higher the value of individual measurements and overall indices, the greater the degree of asymmetry, with zero representing perfect symmetry.

The same researcher measured 10 photographs randomly selected from a collection of pre-surgery images $(n=5)$ and post-surgery images $(n=5)$ to assess intra-observer reliability. The intraclass correlation coefficient suggested excellent reliability $(p<.05 ;$ range $=0.986$ to 0.996$)$.

\section{Patient-reported questionnaire}

Pre-surgery and post-debonding, all patients completed the Orthognathic Quality of Life Questionnaire (OQLQ). OQLQ consists of four domains: Facial Esthetics, Oral Function, Awareness of Dentofacial Esthetics and Social Aspects of

Fig. 4 Two-splint technique - example of a virtual surgical plan of maxillary movement with the intermediate splint in place 

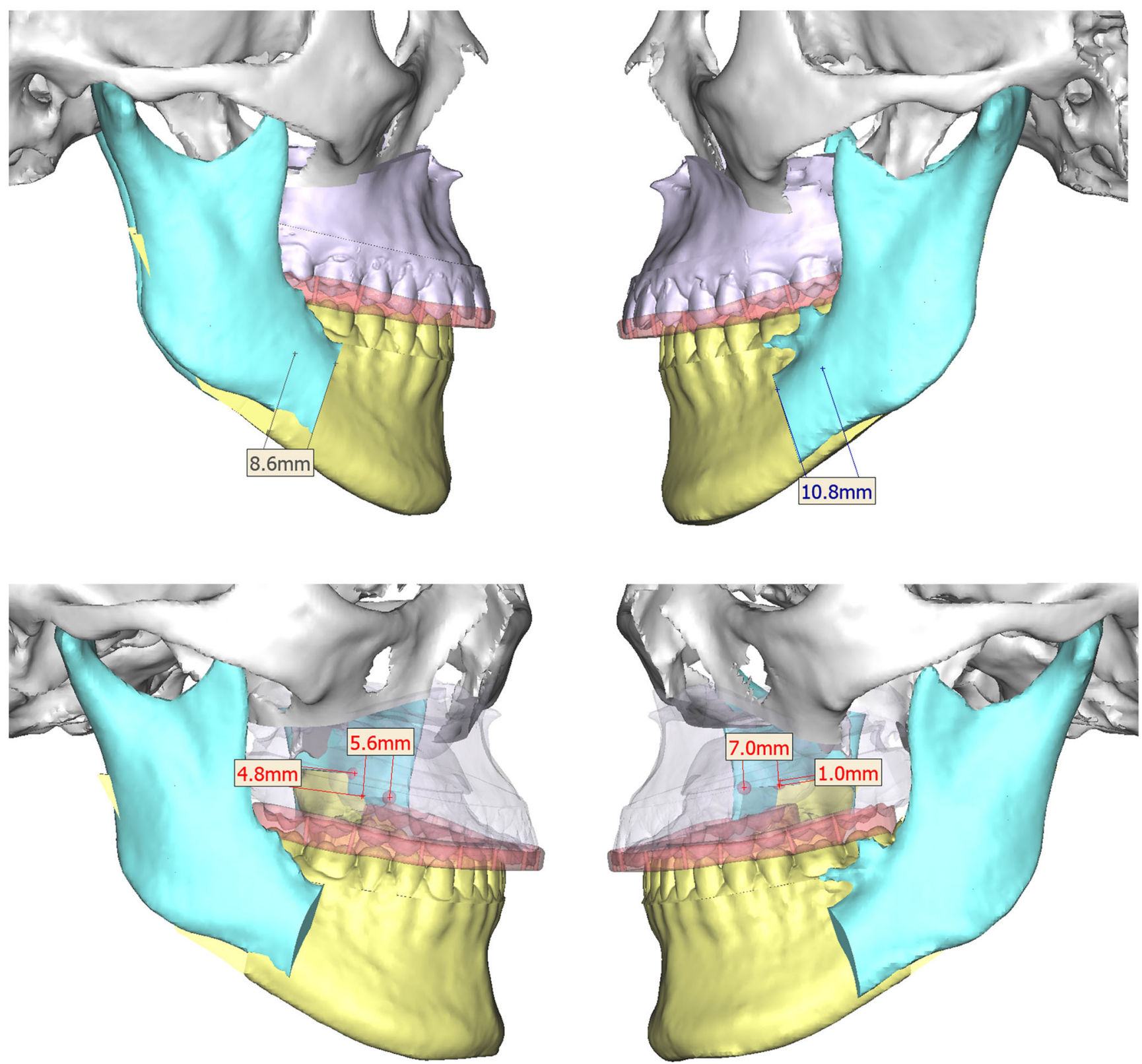

Fig. 5 Two-splint technique - example of a virtual surgical plan of mandibular movement with the final splint in place

Dentofacial Deformity, and a total score ranging from 0 to 88 . A lower score indicates better QoL [27, 28]. The Chinese version of OQLQ was used [29-31].

\section{Statistical analysis}

Demographic data, Facial Symmetry Index and OQLQ scores were analysed with descriptive statistics. Measurements between groups were compared with independent $t$-tests and chi-squared tests where indicated. Before-and-after treatment measurements were compared with paired $t$-tests. All tests were two-tailed; statistical significance was set at $p<0.05$. The Statistical Package for Social Sciences was used (Version 21.0; SPSS Inc., Chicago, Illinois, USA).

\section{Results}

\section{Patients}

Eighty patients met the selection criteria. There were 34 patients in the one-splint group and 46 patients in the two-splint group (Table 1). The most common accessory surgical procedure was genioplasty. The one-splint group had significantly more negative pre-treatment ANB.

\section{Symmetry}

Both groups had significant improvement in intercommissural line deviation after treatment (Table 2). The two-splint group 


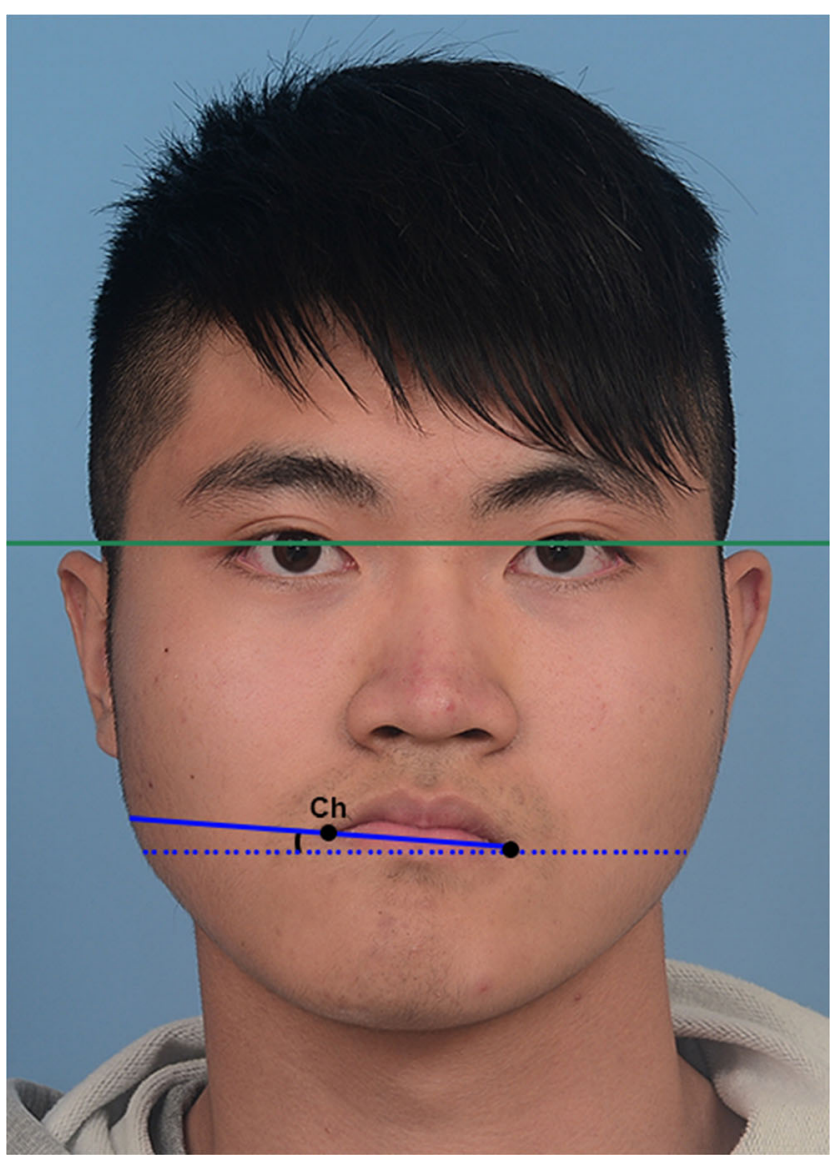

Fig. 6 Intercommissural line deviation. The interpupillary line is shown in green. Ch: Cheilion. Intercommissural line deviation: angle formed between the intercommissural line (blue, $\mathrm{Ch}-\mathrm{Ch}$ ) and the interpupillary line (green) had significant improvement in all midline symmetry measures after treatment. The one-splint group showed no significant improvement in midface deviation but had significant improvement in the remaining midline symmetry measures including the combined Facial Midline Symmetry Index. The two-splint group had significant improvement in all contour symmetry measures after treatment. The one-splint group had significant improvement in middle and lower contour deviation but no significant change in upper contour deviation and the combined Facial Contour Symmetry Index. Both groups had significant improvement in the combined Overall Facial Symmetry Index after treatment.

Comparing the two groups, there were no differences in all the individual and combined symmetry measurements between the groups pre- or post-treatment.

\section{Quality of life}

Both groups had significant improvement in all OQLQ domains and total scores after treatment (Table 3).

Comparing the two groups, all pre-treatment OQLQ domains and total scores except for the Facial Esthetics domain were significantly higher in the one-splint group than the twosplint group. These differences were resolved after treatment, with no significant differences in post-treatment OQLQ domains and total scores between the two groups.
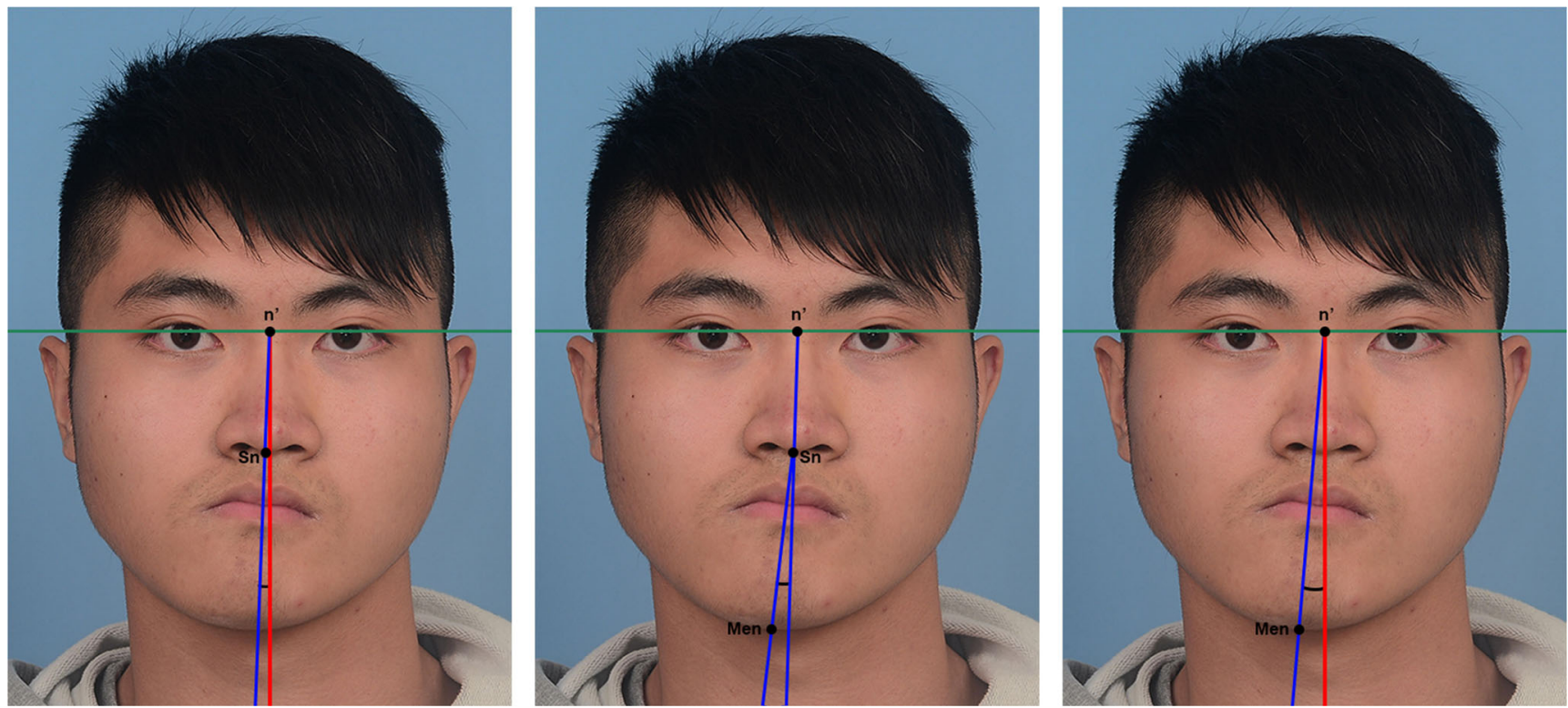

Fig. 7 Representative images of Facial Midline Symmetry Index measurements. The interpupillary line is shown in green. n': Nasion projection on the interpupillary line. Sn: subnasale. Men: menton. (Left) Midface deviation: angle formed between the midface deviation line (blue line, n'-Sn) and facial midline (red line, perpendicular to interpupillary line). (Centre) Chin from midface deviation: angle formed between the midface deviation line (blue line, n'-Sn) and SnMen (blue line). (Right) Chin deviation: angle between n'-Men (blue line) and facial midline (red line) 

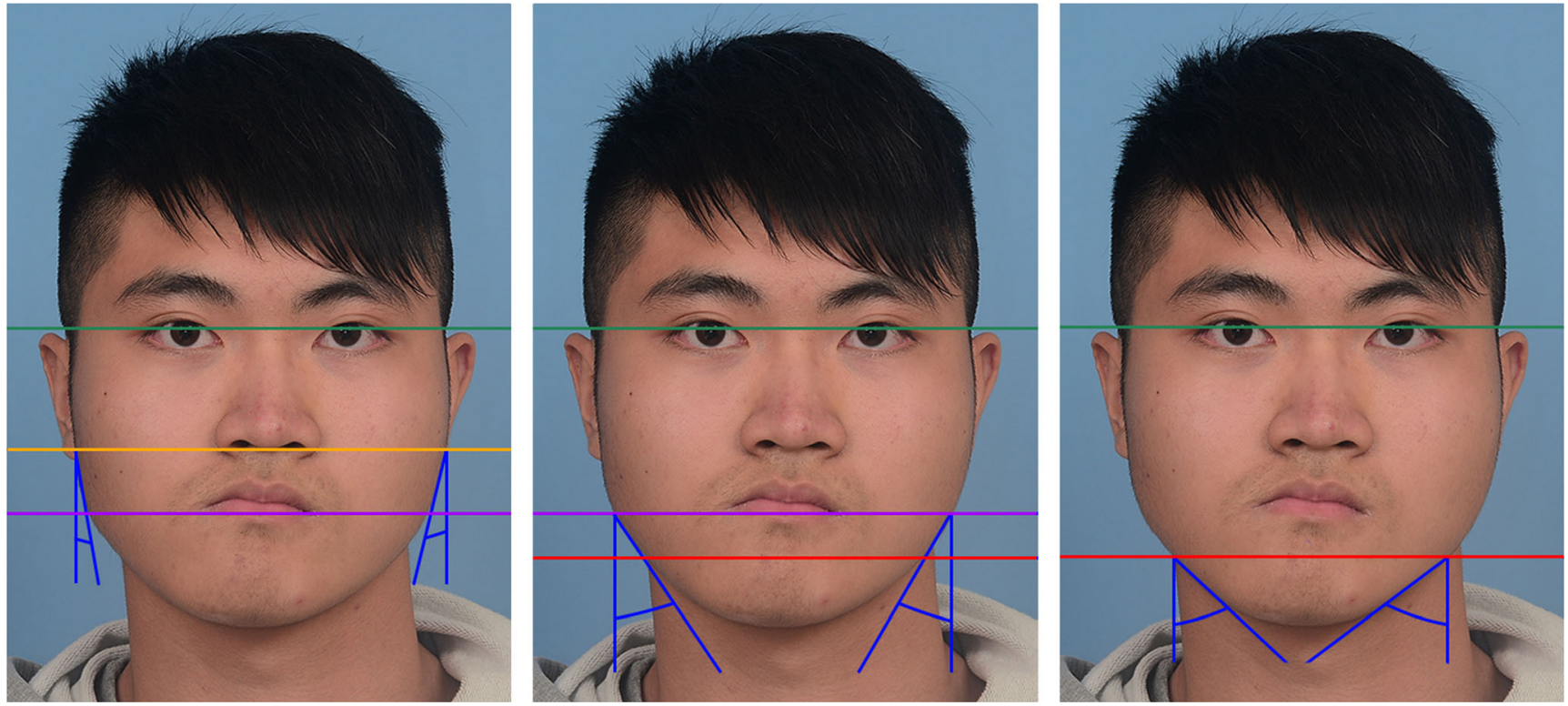

Fig. 8 Representative images of Facial Contour Symmetry Index measurements. The interpupillary line is shown in green. (Left) Upper contour deviation: absolute difference between the right and left upper contour angle, which is the angle between the tangent line from the upper contour to the facial midline (blue lines). (Centre) Middle contour deviation: absolute difference between the right and left middle contour

\section{Discussion}

To reduce risk of bias, there was complete inclusion of all patients meeting the study criteria. However, the groups were not equivalent at baseline, differing in sample size, ANB and OQLQ scores. The larger number of two-splint patients reflects the difference in the number of recruitment years, with the two-splint group being recruited from 3 years of clinical cases (2017-2019) and the one-splint group being drawn from 2 years (2015-2016). Due to general adoption of the two-splint technique in the Center, contemporaneous study groups were not achievable. angle, which is the angle between the tangent line from the middle contour to the facial midline (blue lines). (Right) Lower contour deviation: absolute difference between the right and left lower contour angle, which is the angle between the tangent line from the lower contour to the facial midline (blue line)

The more negative ANB angle in the one-splint group suggests that the one-splint group had more severe skeletal Class III discrepancy than the two-splint group. However, despite the difference in skeletal deformity in the antero-posterior plane, the degree of frontal soft tissue asymmetry measured by the Facial Symmetry Index was not significantly different between the two groups before treatment. All OQLQ domains and total scores except the Facial Esthetics domain were significantly higher in the one-splint group before treatment, suggesting a significantly worse QoL in the one-splint group compared to the two-splint group. This was likely due to the
Table 1 Clinical characteristics of one- and two-splint groups

\begin{tabular}{llll}
\hline Characteristics & One-splint $(n=34)$ & Two-splint $(n=46)$ & $p$-value \\
\hline$\%$ Female $(n)$ & $47 \%(16)$ & $54 \%(25)$ & 0.519 \\
$\begin{array}{l}\text { Age at surgery (years) } \\
\text { (mean } \pm \text { standard deviation) }\end{array}$ & $22 \pm 5$ & $25 \pm 6$ & 0.052 \\
$\begin{array}{l}\text { Initial ANB angle (degrees) } \\
\text { (mean } \pm \text { standard deviation) }\end{array}$ & $-4.9 \pm 2.4$ & $-2.6 \pm 2.2$ & $<0.001^{*}$ \\
$\begin{array}{l}\text { Initial overjet (mm) } \\
\text { (mean } \pm \text { standard deviation) }\end{array}$ & $-2.6 \pm 2.6$ & $-2.2 \pm 3.7$ & 0.293 \\
$\begin{array}{l}\text { Initial overbite (mm) } \\
\text { (mean } \pm \text { standard deviation) }\end{array}$ & $1.0 \pm 2.1$ & $0.6 \pm 2.2$ & 0.417 \\
$\begin{array}{l}\% \text { With maxilla segmentation }(n) \\
\% \text { With mandible segmentation }(n)\end{array}$ & $15 \%(5)$ & $20 \%(9)$ & 0.572 \\
(Kole's Osteotomy) & $3 \%(1)$ & $0 \%(0)$ & 0.242 \\
$\%$ With genioplasty $(n)$ & $53 \%(18)$ & $74 \%(34)$ & 0.052 \\
With mandible contouring $(n)$ & $24 \%(8)$ & $15 \%(7)$ & 0.346 \\
\hline
\end{tabular}

*Statistically significant $p$-values 
Table 2 Facial symmetry index of one- and two-splint groups before and after treatment

\begin{tabular}{|c|c|c|c|c|c|c|c|c|}
\hline \multirow{2}{*}{$\begin{array}{l}\text { Measurement } \\
\text { (higher } \\
\text { score indicates } \\
\text { greater asymmetry) }\end{array}$} & \multicolumn{3}{|c|}{ One-splint $(n=34)$} & \multicolumn{3}{|c|}{ Two-splint $(n=46)$} & \multicolumn{2}{|c|}{ One- vs two-splint } \\
\hline & $\begin{array}{l}\text { Pre-treatment } \\
(\text { mean } \pm \\
\text { standard } \\
\text { deviation) }\end{array}$ & $\begin{array}{l}\text { Post-treatment } \\
\text { (mean } \pm \\
\text { standard } \\
\text { deviation) }\end{array}$ & $p$-value & $\begin{array}{l}\text { Pre-treatment } \\
\text { (mean } \pm \\
\text { standard } \\
\text { deviation) }\end{array}$ & $\begin{array}{l}\text { Post-treatment } \\
\text { (mean } \pm \\
\text { standard } \\
\text { deviation) }\end{array}$ & $p$-value & $\begin{array}{l}\text { Pre-treatment } \\
p \text {-value }\end{array}$ & $\begin{array}{l}\text { Post-treatment } \\
p \text {-value }\end{array}$ \\
\hline $\begin{array}{l}\text { Intercommissural } \\
\text { line deviation } \\
\text { (degrees) }\end{array}$ & $2.0 \pm 1.4$ & $1.1 \pm 0.9$ & $0.001 *$ & $2.5 \pm 1.5$ & $1.1 \pm 1.0$ & $<0.001 *$ & 0.131 & 0.761 \\
\hline $\begin{array}{l}\text { Midface deviation } \\
\quad \text { (degrees) }\end{array}$ & $0.5 \pm 0.8$ & $0.4 \pm 0.6$ & 0.162 & $0.6 \pm 0.9$ & $0.4 \pm 0.7$ & $0.020^{*}$ & 0.793 & 0.843 \\
\hline $\begin{array}{l}\text { Chin from midface deviation } \\
\text { (degrees) }\end{array}$ & $5.6 \pm 2.8$ & $1.8 \pm 1.6$ & $<0.001 *$ & $5.5 \pm 2.6$ & $1.5 \pm 1.6$ & $<0.001 *$ & 0.855 & 0.412 \\
\hline $\begin{array}{l}\text { Chin deviation } \\
\text { (degrees) }\end{array}$ & $3.8 \pm 1.9$ & $1.2 \pm 0.9$ & $<0.001^{*}$ & $3.7 \pm 1.4$ & $1.1 \pm 1.0$ & $<0.001 *$ & 0.876 & 0.567 \\
\hline $\begin{array}{l}\text { Facial midline } \\
\text { symmetry index }\end{array}$ & $9.9 \pm 4.8$ & $3.4 \pm 2.5$ & $<0.001 *$ & $9.7 \pm 4.0$ & $3.0 \pm 2.6$ & $<0.001 *$ & 0.869 & 0.501 \\
\hline $\begin{array}{l}\text { Upper contour } \\
\text { deviation (degrees) }\end{array}$ & $3.4 \pm 3.1$ & $3.2 \pm 2.5$ & 0.550 & $3.9 \pm 2.8$ & $2.5 \pm 1.6$ & $0.013^{*}$ & 0.430 & 0.216 \\
\hline $\begin{array}{l}\text { Middle contour } \\
\text { deviation (degrees) }\end{array}$ & $3.3 \pm 2.3$ & $2.8 \pm 4.3$ & $0.041 *$ & $3.8 \pm 2.4$ & $2.1 \pm 1.5$ & $<0.001 *$ & 0.378 & 0.347 \\
\hline $\begin{array}{l}\text { Lower contour } \\
\text { deviation (degrees) }\end{array}$ & $4.7 \pm 4.3$ & $3.1 \pm 2.7$ & $0.011 *$ & $4.3 \pm 3.6$ & $2.8 \pm 2.2$ & $0.020 *$ & 0.584 & 0.630 \\
\hline $\begin{array}{l}\text { Facial contour } \\
\text { symmetry Index }\end{array}$ & $11.5 \pm 7.0$ & $9.1 \pm 6.3$ & 0.078 & $12.0 \pm 6.4$ & $7.4 \pm 3.6$ & $<0.001 *$ & 0.654 & 0.138 \\
\hline $\begin{array}{l}\text { Overall facial } \\
\text { symmetry index }\end{array}$ & $23.3 \pm 11.7$ & $13.6 \pm 7.3$ & $<0.001 *$ & $24.2 \pm 10.3$ & $11.5 \pm 5.0$ & $<0.001 *$ & 0.658 & 0.123 \\
\hline
\end{tabular}

*Statistically significant $p$-values

pre-treatment difference in ANB. OQLQ scores have been found to be significantly negatively correlated to ANB in Japanese Class III OGS patients, suggesting QoL is adversely affected by the degree of skeletal discrepancy [32]. Hence, due to the study design, there were differences between the study groups in terms of the sample size, severity of skeletal deformity and the level of impairment on QoL. An additional limitation was the lack of homogeneity in surgical procedures done within the two groups, with a percentage of patients in each group requiring segmental osteotomies, genioplasty or mandible contouring. However, there were no significant differences in the percentage of segmental osteotomies,

Table 3 OQLQ of one- and two-splint groups before and after treatment

\begin{tabular}{|c|c|c|c|c|c|c|c|c|}
\hline \multirow{2}{*}{$\begin{array}{l}\text { Measurement } \\
\text { (higher score } \\
\text { indicates poorer QoL) }\end{array}$} & \multicolumn{3}{|c|}{ One-splint $(n=34)$} & \multicolumn{3}{|c|}{ Two-splint $(n=46)$} & \multicolumn{2}{|c|}{ One- vs two-splint } \\
\hline & $\begin{array}{l}\text { Pre-treatment } \\
\text { (mean } \pm \\
\text { standard } \\
\text { deviation) }\end{array}$ & $\begin{array}{l}\text { Post-treatment } \\
\text { (mean } \pm \\
\text { standard } \\
\text { deviation) }\end{array}$ & $p$-value & $\begin{array}{l}\text { Pre-treatment } \\
\text { (mean } \pm \\
\text { standard } \\
\text { deviation) }\end{array}$ & $\begin{array}{l}\text { Post-treatment } \\
\text { (mean } \pm \\
\text { standard } \\
\text { deviation) }\end{array}$ & $p$-value & $\begin{array}{l}\text { Pre-treatment } \\
p \text {-value }\end{array}$ & $\begin{array}{l}\text { Post-treatment } \\
p \text {-value }\end{array}$ \\
\hline $\begin{array}{l}\text { Facial Esthetics } \\
(0 \text { to } 20)\end{array}$ & $14.1 \pm 3.2$ & $6.2 \pm 4.0$ & $<0.001^{*}$ & $12.9 \pm 4.5$ & $6.3 \pm 3.4$ & $<0.001 *$ & 0.183 & 0.924 \\
\hline $\begin{array}{l}\text { Oral Function } \\
(0 \text { to } 20)\end{array}$ & $12.7 \pm 4.1$ & $4.7 \pm 2.9$ & $<0.001 *$ & $9.1 \pm 4.5$ & $4.7 \pm 2.8$ & $<0.001 *$ & $0.001 *$ & 0.912 \\
\hline $\begin{array}{l}\text { Awareness of } \\
\text { Dentofacial } \\
\text { Esthetics } \\
(0 \text { to } 16)\end{array}$ & $10.8 \pm 3.1$ & $5.3 \pm 3.1$ & $<0.001 *$ & $7.9 \pm 3.9$ & $4.6 \pm 2.7$ & $<0.001 *$ & $0.001 *$ & 0.316 \\
\hline $\begin{array}{l}\text { Social Aspect of Dentofacial } \\
\text { Deformity } \\
(0 \text { to } 32)\end{array}$ & $20.9 \pm 6.9$ & $7.6 \pm 6.8$ & $<0.001^{*}$ & $15.2 \pm 8.5$ & $7.8 \pm 5.8$ & $<0.001 *$ & $0.002 *$ & 0.689 \\
\hline $\begin{array}{l}\text { OQLQ Total } \\
(0 \text { to } 88)\end{array}$ & $58.4 \pm 13.5$ & $23.7 \pm 15.1$ & $<0.001^{*}$ & $45.1 \pm 19.3$ & $23.3 \pm 12.1$ & $<0.001 *$ & $0.001 *$ & 0.902 \\
\hline
\end{tabular}

*Statistically significant $p$-values 
genioplasty or mandible contouring between the two study groups. Any interpretations of the results must be coloured by these limitations.

Compared to 2D imaging, 3D imaging provides better diagnosis of facial asymmetry, surgical planning and treatment transfer. Because of this, hard tissue symmetry is more easily achieved with 3D surgical planning compared with 2D planning and can largely be considered a solved problem [13, 14 , $17,18]$. Unfortunately, acceptable hard tissue symmetry does not necessarily translate into good soft tissue symmetry, and patients with symmetric hard tissues may still have asymmetric soft tissues [7, 9, 33]. A recent study of Class III facial asymmetry patients found that despite bimaxillary OGS, soft tissue asymmetry did not change significantly after treatment and throughout 24-month follow-up [34]. Despite this, OGS literature is still largely focused on evaluating hard tissue metrics and execution of hard tissue plans, with significantly less attention on soft tissue outcomes [13, 14, 17, 35, 36]. In addition, the focus of most asymmetry studies is on midline structures and the deviation from the mid-sagittal plane [13, $14,17,37,38]$. However, patients seeking OGS for asymmetry can present with significant contour asymmetry.

Whilst accurate execution of the surgical plan and the resulting hard tissue midline symmetry are necessary outcome metrics, they are insufficient to define surgical success [16]. Patients request OGS not only to remedy deformities and functional problems but also to enhance their body image and QoL and reduce perceived social stigma. OGS may help to enhance self-perceived attractiveness and self-confidence of individuals [39]. Frontal soft tissue symmetry is the only metric that is easily assessed visually by patients and in practice is likely inspected daily in the mirror $[16,40]$. The patient's perceived frontal improvement translates into patient satisfaction and psychosocial benefits $[16,18,39]$. For this reason, this study focused on frontal soft tissue outcomes, including soft tissue contour, as well as patient-reported QoL.

In OGS, the two-splint technique is classically considered the gold standard for surgical plan transference, whereas onesplint technique is controversial $[5,8]$. The addition of 3D planning to one-splint technique has improved visualisation of yaw asymmetry [14] and enhanced hard and soft tissue results in asymmetry patients [13-16]. Nonetheless, with the one-splint technique, there was no precise way of translating the plan to the surgical field, with significant deviations from the $3 \mathrm{D}$ plan seen $[13,14]$. It was hypothesised that with more accurate implementation of the 3D surgical plan, the twosplint technique might produce better soft tissue symmetry.

This study found that the two-splint technique may be better able to improve contour symmetry than the one-splint technique, as the two-splint technique was able to improve all symmetry measurements, whereas the one-splint technique produced no significant improvement in Midface Deviation, Upper Contour Deviation measurements and the combined
Facial Contour Symmetry Index. However, both the onesplint and two-splint techniques significantly improved all other symmetry measurements as well as the combined Facial Midline Symmetry Index and Overall Facial Symmetry Index. Furthermore, there were no significant differences in any facial symmetry measures after treatment between the one-splint and two-splint groups.

This lack of significant difference in final outcomes can be explained by the fact that the one-splint technique was developed specifically for frontal soft tissue asymmetry $[6,7,41]$. The intra-operative checkpoints emphasised in the one-splint technique were designed based on measures used in the Facial Midline Symmetry Index [7]. The focus on midline structures may have also unduly influenced the results of the Overall Facial Symmetry Index. The one-splint technique was found to produce adequate frontal soft tissue symmetry in patients $[7,15,16]$. Although the one-splint technique produces significant error in MMC pitch compared to the 3D surgical plan [13], inaccuracies in hard tissue pitch may manifest more in the lateral profile and less in frontal soft tissue symmetry.

One previous study compared the one-splint, free-hand MMC positioning technique against a guided maxilla positioning technique [18]. Compared with patients who had 2D surgical planning and one-splint technique OGS, patients who had 3D surgical planning and printed extra-skeletal MMC positioning guides showed both better hard tissue symmetry as well as better patient satisfaction after OGS. Although the study did not use an intermediate splint to position the maxilla, the findings suggest that guided MMC positioning has superior results over free-hand MMC positioning. However, the fact that the one-splint group used 2D planning whilst the guided MMC positioning group used 3D planning makes it difficult to draw firm conclusions, as 3D planning with onesplint technique has shown good results in asymmetric patients [13-16].

With regard to QoL, this study found that both the onesplint and the two-splint groups experienced significant improvement in OQLQ scores after treatment, which is similar to other studies on East Asian Class III OGS patients [30-32]. In addition, despite the worse QoL in the one-splint group pretreatment, there was no significant difference between the two groups in OQLQ post-treatment, suggesting a similar level of QoL was attained. However, a direct comparison of QoL changes between the two groups may not be meaningful due to the significantly worse pre-treatment QoL in the one-splint group.

Finally, the authors' Craniofacial Center has been using the surgery-first approach for more than 30 years and has an established surgery-first practice and clinical protocol. However, surgical outcomes of the surgery-first technique can be variable [42], and the results of this study may not be generalizable to surgeons and orthodontists who have limited experience in the surgery-first approach. 
To the best of the authors' knowledge, this is the first study that compares the 3D planned one-splint technique with the 3D planned two-splint technique. The results suggest that the two-splint technique may better improve contour symmetry, but there are no significant differences in overall soft tissue symmetry and in QoL outcomes between the two techniques. However, although frontal soft tissue and post-treatment QoL outcomes are similar, two-splint technique has intra-operative benefits over one-splint as it is also less surgically demanding, has less of a learning curve and depends less heavily on surgeon experience [7, 12]. A simpler and less demanding surgery may reduce operative time, intra-operative blood loss and post-operative hospital stay [43, 44]. This might lead to better patient experience and higher patient satisfaction immediately post-operatively. This study did not investigate these parameters, and future work should investigate these questions.

\section{Conclusions}

OGS treatment with both the one-splint and two-splint techniques significantly improves soft tissue symmetry and QoL in skeletal Class III asymmetry patients. Two-splint technique may better improve contour symmetry. There were no differences in soft tissue symmetry and QoL after OGS treatment in skeletal Class III asymmetry patients treated with either the one-splint or two-splint technique.

Supplementary Information The online version contains supplementary material available at https://doi.org/10.1007/s00784-021-03967-9.

Acknowledgements We thank Mr. Jung-Yu Wu and Miss Yi-Hsieh Wang for data collection and collaboration. The research was supported by Chang Gung Memorial Hospital, Taiwan, grant nos. CMRPG5G0023, CMRPG5F0053, CMRPG5F0063, and CMRPG5K0052.

Author contribution Jing Hao Ng: substantial contributions to analysis and interpretation of data; drafting the article; gave final approval of the version to be published; agreement to be accountable for all aspects of the work in ensuring that questions related to the accuracy or integrity of any part of the work are appropriately investigated and resolved. Yu-Fang Liao: substantial contributions to conception and design, acquisition of data, analysis and interpretation of data; revising the article critically for important intellectual content; gave final approval of the version to be published; agreement to be accountable for all aspects of the work in ensuring that questions related to the accuracy or integrity of any part of the work are appropriately investigated and resolved. Ying-An Chen, Yuh-Jia Hsieh, Chuan-Fong Yao, Yu-Ray Chen: substantial contributions to acquisition of data, analysis and interpretation of data; revising the article critically for important intellectual content; gave final approval of the version to be published; agreement to be accountable for all aspects of the work in ensuring that questions related to the accuracy or integrity of any part of the work are appropriately investigated and resolved.
Funding information The research was supported by Chang Gung Memorial Hospital, Taiwan, grant nos. CMRPG5G0023, CMRPG5F0053, CMRPG5F0063, and CMRPG5K0052.

\section{Declarations}

Ethics approval All procedures performed in the study were in accordance with the ethical standards of the institutional research committee and with the 1964 Helsinki Declaration and its later amendments or comparable ethical standards.

Consent to participate Due to the retrospective design of the study, the need for informed consent was waived by the Institutional Review Board (IRB No.: 202000503B0).

Consent to publish The authors affirm that human research participants provided informed consent for publication of the images in Figs. 1, 3, 6, 7 and 8 .

Conflict of interest All authors declare that they have no conflict of interest.

Open Access This article is licensed under a Creative Commons Attribution 4.0 International License, which permits use, sharing, adaptation, distribution and reproduction in any medium or format, as long as you give appropriate credit to the original author(s) and the source, provide a link to the Creative Commons licence, and indicate if changes were made. The images or other third party material in this article are included in the article's Creative Commons licence, unless indicated otherwise in a credit line to the material. If material is not included in the article's Creative Commons licence and your intended use is not permitted by statutory regulation or exceeds the permitted use, you will need to obtain permission directly from the copyright holder. To view a copy of this licence, visit http://creativecommons.org/licenses/by/4.0/.

\section{References}

1. Lee S, McGrath C, Samman N (2008) Impact of orthognathic surgery on quality of life. J Oral Maxillofac Surg 66:1194-1199

2. Murphy C, Kearns G, Sleeman D, Cronin M, Allen PF (2011) The clinical relevance of orthognathic surgery on quality of life. Int $\mathrm{J}$ Oral Maxillofac Surg 40:926-930

3. Ryan FS, Barnard M, Cunningham SJ (2012) Impact of dentofacial deformity and motivation for treatment: a qualitative study. Am J Orthod Dentofac Orthop 141:734-742

4. Yu D, Wang F, Wang X, Fang B, Shen SG (2013) Presurgical motivations, self-esteem, and oral health of orthognathic surgery patients. J Craniofac Surg 24:743-747

5. Lapp TH (1999) Bimaxillary surgery without the use of an intermediate splint to position the maxilla. J Oral Maxillofac Surg 57: $57-60$

6. Bergeron L, Yu CC, Chen YR (2008) Single-splint technique for correction of severe facial asymmetry: correlation between intraoperative maxillomandibular complex roll and restoration of mouth symmetry. Plast Reconstr Surg 122:1535-1541

7. Yu CC, Bergeron L, Lin CH, Chu YM, Chen YR (2009) Singlesplint technique in orthognathic surgery: intraoperative checkpoints to control facial symmetry. Plast Reconstr Surg 124:879-886

8. Ellis E 3rd (1999) Bimaxillary surgery using an intermediate splint to position the maxilla. J Oral Maxillofac Surg 57:53-56 
9. Hwang H-S, Yuan D, Jeong K-H, Uhm G-S, Cho J-H, Yoon S-J (2012) Three-dimensional soft tissue analysis for the evaluation of facial asymmetry in normal occlusion individuals. Korean J Orthod 42:56-63

10. Kim YH, Jeon J, Rhee JT, Hong J (2010) Change of lip cant after bimaxillary orthognathic surgery. J Oral Maxillofac Surg 68:11061111

11. Ko EW, Huang CS, Chen YR (2009) Characteristics and corrective outcome of face asymmetry by orthognathic surgery. J Oral Maxillofac Surg 67:2201-2209

12. Hatef DA, Hollier LH Jr (2009) Discussion. Single-splint technique in orthognathic surgery: intraoperative checkpoints to control facial symmetry. Plast Reconstr Surg 124:887

13. Ko EW, Lin CH, Chen YA, Chen YR (2018) Enhanced surgical outcomes in patients with skeletal class III facial asymmetry by 3dimensional surgical simulation. J Oral Maxillofac Surg 76:10731083

14. Udomlarptham N, Lin CH, Wang YC, Ko EW (2018) Does twodimensional vs. three-dimensional surgical simulation produce better surgical outcomes among patients with class III facial asymmetry? Int J Oral Maxillofac Surg 47:1022-1031

15. Liao YF, Chen YF, Yao CF, Chen YA, Chen YR (2019) Long-term outcomes of bimaxillary surgery for treatment of asymmetric skeletal class III deformity using surgery-first approach. Clin Oral Investig 23:1685-1693

16. Liao YF, Chen YA, Chen YC, Chen YR (2020) Outcomes of conventional versus virtual surgical planning of orthognathic surgery using surgery-first approach for class III asymmetry. Clin Oral Investig 24:1509-1516

17. De Riu G, Meloni SM, Baj A, Corda A, Soma D, Tullio A (2014) Computer-assisted orthognathic surgery for correction of facial asymmetry: results of a randomised controlled clinical trial. $\mathrm{Br} \mathrm{J}$ Oral Maxillofac Surg 52:251-257

18. Wu TY, Lin HH, Lo LJ, Ho CT (2017) Postoperative outcomes of two- and three-dimensional planning in orthognathic surgery: a comparative study. J Plast Reconstr Aesthet Surg 70:1101-1111

19. Haraguchi S, Takada K, Yasuda Y (2002) Facial asymmetry in subjects with skeletal Class III deformity. Angle Orthod 72:28-35

20. Meyer-Marcotty P, Stellzig-Eisenhauer A, Bareis U, Hartmann J, Kochel J (2011) Three-dimensional perception of facial asymmetry. Eur J Orthod 33:647-653

21. Takatsuji H, Kobayashi T, Kojima T, Hasebe D, Izumi N, Saito I, Saito C (2015) Effects of orthognathic surgery on psychological status of patients with jaw deformities. Int J Oral Maxillofac Surg 44:1125-1130

22. Association WM (2013) World Medical Association Declaration of Helsinki: ethical principles for medical research involving human subjects. JAMA 310:2191-2194

23. von Elm E, Altman DG, Egger M, Pocock SJ, Gøtzsche PC, Vandenbroucke JP (2008) The Strengthening the Reporting of Observational Studies in Epidemiology (STROBE) statement: guidelines for reporting observational studies. J Clin Epidemiol 61:344-349

24. Liao YF, Chiu YT, Huang CS, Ko EW, Chen YR (2010) Presurgical orthodontics versus no presurgical orthodontics: treatment outcome of surgical-orthodontic correction for skeletal class III open bite. Plast Reconstr Surg 126:2074-2083

25. Ettorre G, Weber M, Schaaf H, Lowry JC, Mommaerts MY, Howaldt HP (2006) Standards for digital photography in craniomaxillo-facial surgery - part I: basic views and guidelines. J Craniomaxillofac Surg 34:65-73
26. Schaaf H, Streckbein P, Ettorre G, Lowry JC, Mommaerts MY, Howaldt HP (2006) Standards for digital photography in craniomaxillo-facial surgery — part II: additional picture sets and avoiding common mistakes. J Craniomaxillofac Surg 34:366-377

27. Cunningham SJ, Garratt AM, Hunt NP (2000) Development of a condition-specific quality of life measure for patients with dentofacial deformity: I. Reliability of the instrument. Community Dent Oral Epidemiol 28:195-201

28. Cunningham SJ, Garratt AM, Hunt NP (2002) Development of a condition-specific quality of life measure for patients with dentofacial deformity: II. Validity and responsiveness testing. Community Dent Oral Epidemiol 30:81-90

29. Lee S, McGrath C, Samman N (2007) Quality of life in patients with dentofacial deformity: a comparison of measurement approaches. Int J Oral Maxillofac Surg 36:488-492

30. Sun H, Shang HT, He LS, Ding MC, Su ZP, Shi YL (2018) Assessing the quality of life in patients with dentofacial deformities before and after orthognathic surgery. J Oral Maxillofac Surg 76: 2192-2201

31. Ni J, Song S, Zhou N (2019) Impact of surgical orthodontic treatment on quality of life in Chinese young adults with class III malocclusion: a longitudinal study. BMC Oral Health 19:109

32. Tachiki C, Nishii Y, Takaki T, Sueishi K (2018) Condition-specific quality of life assessment at each stage of class III surgical orthodontic treatment - a prospective study. Bull Tokyo Dent Coll 59:114

33. Lee TY, Kim KH, Yu HS, Kim KD, Jung YS, Baik HS (2014) Correlation analysis of three-dimensional changes of hard and soft tissues in class III orthognathic surgery patients using cone-beam computed tomography. J Craniofac Surg 25:1530-1540

34. Da Pozzo F, Gibelli D, Beltramini GA, Dolci C, Giannì AB, Sforza C (2020) The effect of orthognathic surgery on soft-tissue facial asymmetry: a longitudinal three-dimensional analysis. J Craniofac Surg

35. Schneider D, Kammerer PW, Hennig M, Schon G, Thiem DGE, Bschorer R (2019) Customized virtual surgical planning in bimaxillary orthognathic surgery: a prospective randomized trial. Clin Oral Investig 23:3115-3122

36. Hanafy M, Akoush Y, Abou-ElFetouh A, Mounir RM (2020) Precision of orthognathic digital plan transfer using patientspecific cutting guides and osteosynthesis versus mixed analoguedigitally planned surgery: a randomized controlled clinical trial. Int J Oral Maxillofac Surg 49:62-68

37. Suzuki-Okamura E, Higashihori N, Kawamoto T, Moriyama K (2015) Three-dimensional analysis of hard and soft tissue changes in patients with facial asymmetry undergoing 2-jaw surgery. Oral Surg Oral Med Oral Pathol Oral Radiol 120:299-306

38. Freudlsperger $\mathrm{C}$, Rückschloß T, Ristow $\mathrm{O}$, Bodem J, Kargus $\mathrm{S}$, Seeberger R, Engel M, Hoffmann J, Mertens C (2017) Effect of occlusal plane correction on lip cant in two-jaw orthognathic surgery - a three-dimensional analysis. J Craniomaxillofac Surg 45:1026-1030

39. Lee LW, Chen SH, Yu CC, Lo LJ, Lee SR, Chen YR (2007) Stigma, body image, and quality of life in women seeking orthognathic surgery. Plast Reconstr Surg 120:225-231

40. Chen YR, Huang CSD (2019) 3D clinical evaluation of face. In: Chen YR, Huang CSD (eds) Surgery-First Approach in Orthognathic Surgery, 2nd edn. Taiwan Cleft Palate-Craniofacial Association, Taiwan, pp 31-54

41. Chou PY, Denadai R, Yao CF, Chen YA, Chang CS, Lin CC, Liao YF, Liou EJW, Ko EW, Lo LJ, Huang CS, Chen YR (2020) History and evolution of orthognathic surgery at Chang Gung 
Craniofacial Center: lessons learned from 35-year experience. Ann Plast Surg 84:S60-s68

42. Wei H, Liu Z, Zang J, Wang X (2018) Surgery-first/earlyorthognathic approach may yield poorer postoperative stability than conventional orthodontics-first approach: a systematic review and meta-analysis. Oral Surg Oral Med Oral Pathol Oral Radiol 126:107-116

43. Choi BK, Yang EJ, Oh KS, Lo LJ (2013) Assessment of blood loss and need for transfusion during bimaxillary surgery with or without maxillary setback. J Oral Maxillofac Surg 71:358-365
44. Salma RG, Al-Shammari FM, Al-Garni BA, Al-Qarzaee MA (2017) Operative time, blood loss, hemoglobin drop, blood transfusion, and hospital stay in orthognathic surgery. Oral Maxillofac Surg 21:259-266

Publisher's note Springer Nature remains neutral with regard to jurisdictional claims in published maps and institutional affiliations. 